Arq. Bras. Med. Vet. Zootec., v.60, n.2, p.283-288, 2008

\title{
Fatores de risco para mastite subclínica em vacas leiteiras
}

\author{
[Risk factors for subclinical mastitis in dairy cows]
}

\author{
C.M. Coentrão ${ }^{1}$, G.N. Souza ${ }^{2 *}$, J.R.F. Brito ${ }^{2}$, M.A.V. Paiva e Brito ${ }^{2}$, W. Lilenbaum ${ }^{3}$ \\ ${ }^{1}$ Aluna de pós-graduação - UFF - Niterói, RJ \\ ${ }^{2}$ Embrapa Gado de Leite \\ Rua Eugênio do Nascimento, 610 \\ 36038-330 - Juiz de Fora, MG \\ ${ }^{3}$ Instituto Biomédico - UFF - Niterói, RJ
}

\begin{abstract}
RESUMO
Os fatores de risco para mastite subclínica (CCS > 200.000 células/ml) foram estudados em 2.657 vacas, de 24 rebanhos de Minas Gerais. Cada rebanho foi visitado três vezes entre novembro de 2005 e junho de 2006. Amostras de leite $(n=3.987)$ de vacas em lactação foram examinadas para contagem de células somáticas (CCS), e um questionário foi aplicado para obtenção de dados dos animais e do manejo do rebanho. Os valores para a média, mediana e desvio-padrão da CCS foram 608.000, 219.000 e 967.000 células $/ \mathrm{ml}$, respectivamente. Os fatores de risco para mastite subclínica foram: animais com a base do úbere junto ou abaixo do jarrete, rachaduras ou fissuras nas partes de borracha do equipamento de ordenha, inadequação das teteiras, deficiência de limpeza dos pulsadores, falta de treinamento dos ordenhadores, não-utilização de diagnóstico microbiológico para mastite, imersão do conjunto de teteiras em solução desinfetante entre a ordenha de animais distintos, e inserção total da cânula de antibiótico nos tetos na secagem da vaca. A alta variação da CCS (608.000 \pm 967.000 células $/ \mathrm{ml})$ sugere que outros fatores, como o número de quartos mamários infectados e os patógenos envolvidos, podem ter influenciado os resultados. A metodologia utilizada não permitiu identificar todos os fatores que poderiam aumentar a CCS. Contudo, os resultados são úteis para aprimorar os programas de controle da mastite.
\end{abstract}

Palavras-chave: bovino, mastite, fatores de risco, contagem de células somáticas

\begin{abstract}
This study was carried out to identify risk factors for subclinical mastitis (SCC $>200,000$ cells $/ \mathrm{ml})$. A total of 2,657 lactating cows from 24 herds in the State of Minas Gerais, Brazil, were included in the study. Each farm was visited three times in an 8-month period from November 2005 to June 2006. At each visit, all milking cows were examined for clinical mastitis by a single observer. A total of 3,987 milk samples were examined for somatic cell counts (SCC). The mean, median, and standard deviation values for SCC were, respectively, 608,000, 219,000, and 967,000 cells/ml. Risk factors for subclinical mastitis were: udder positioned at the same height or below the hock, presence of cracks or fissures in the rubber parts of the milking machine, inadequacy of teat cups, infrequent and unsuitable scheme for cleaning the pulsators, milkers unable to operate the milking equipments, no information about the mastitis pathogens present in the herd, immersion of teat cups in disinfectant solution between milkings, and total insertion of cannula in teats during antibiotic treatment. The high variation of the SCC values $(608,000 \pm 967,000$ cells $/ \mathrm{ml})$ suggests that other factors such as number of infected mammary quarters and pathogens involved could have influenced the results. The used methodology did not allow to identify all risk factors that increase SCC. Therefore, the results can also be used to improve the currently mastitis control programs adopted by those herds.
\end{abstract}

Keywords: bovine, mastitis, risk factors, somatic cell count

Recebido em 24 de outubro de 2007

Aceito em 10 de fevereiro de 2008

*Autor para correspondência (corresponding author)

E-mail: gnsouza@cnpgl.embrapa.br 


\section{INTRODUÇÃO}

A contagem de células somáticas (CCS) no leite é o indicador mais usado em programas de controle e prevenção da mastite em todo o mundo. Vários fatores podem influenciar a variação da CCS, sendo citados a ordem de parto, período de lactação, mês e estação do ano (Schepers et al., 1997; Laevens et al., 1997; Souza et al., 2005b; Cunha et al., 2008). No entanto, a ocorrência de infecção intramamária é o principal fator responsável pela variação da CCS (Harmon, 1994). Dohoo e Leslie (1991) avaliaram a CCS de vacas em intervalos de 28 dias e observaram que o limite de 200.000 células/ml foi o mais indicado para estimar uma nova infecção intramamária.

Estudos epidemiológicos prévios sobre fatores de risco identificaram características relacionadas ao animal, ao ambiente, aos procedimentos de manejo e ao equipamento de ordenha, associadas à mastite bovina e à variação da CCS (Peeler et al., 2000; Ott e Novak, 2001; Berry e Hillerton, 2002; Souza et al., 2005a). Em programas de controle e prevenção de mastite, deve-se levar em consideração não apenas os fatores de risco relacionados às características de animal, de ambiente, de manejo e de equipamento de ordenha, mas também o suporte laboratorial, conforme descrito pelo NMC (Recommended..., 2001). A importância do diagnóstico microbiológico é discutida por Sol et al. (1997), Brito et al. (1999) e Osteras et al. (1999), pois fornece o padrão de infecção do rebanho, o que auxiliaria no controle e na erradicação de determinados patógenos.

No Brasil, há poucos trabalhos sobre fatores de risco para mastite. Souza et al. (2005b) realizaram trabalho sobre fatores de risco para mastite e verificaram que a metodologia de análise permitiu a identificação de possíveis fatores de risco para altas CCS do rebanho e para patógenos específicos da mastite. $\mathrm{O}$ objetivo do presente trabalho foi identificar e quantificar fatores de risco para CCS acima de 200.000 células $/ \mathrm{ml}$ de vacas leiteiras oriundas de rebanhos ordenhados mecanicamente.

\section{MATERIAL E MÉTODOS}

O estudo foi realizado em rebanhos bovinos leiteiros localizados na Zona da Mata do estado de Minas Gerais, no período de julho de 2004 a outubro de 2005. Utilizou-se a base de dados do Laboratório de Qualidade do Leite da Embrapa Gado de Leite, após a análise do histórico de, pelo menos, um ano da CCS de 175 rebanhos. Foram selecionados 24 rebanhos para obtenção de dados epidemiológicos e CCS das vacas em lactação. O período de coleta das amostras de leite foi de oito meses e, para a seleção dos rebanhos, além do histórico da CCS, foram levadas em consideração a existência de equipamento de ordenha na propriedade, a disponibilidade e o interesse do proprietário em participar do estudo e a distância entre as propriedades e o laboratório. $\mathrm{O}$ estudo foi realizado em 24 rebanhos localizados nos municípios de Juiz de Fora (6), Coronel Pacheco (6), Matias Barbosa (4), Rio Preto (8). Durante o período de coleta das amostras de leite, foram anotadas informações em um questionário sobre características individuais: ordem de parto, período de lactação, profundidade e equilíbrio do úbere, presença de lesão nos tetos e escape de leite, e sobre procedimentos relacionados ao controle $\mathrm{e}$ prevenção de mastite. A avaliação da profundidade do úbere foi realizada considerando a altura da base do úbere em relação ao jarrete e do equilíbrio e simetria entre os quartos posteriores em relação ao ligamento mediano do úbere. $\mathrm{O}$ questionário compreendia uma seção com entrevista com ordenhadores e gerentes dos rebanhos, outra com observações visuais de equipamento e procedimentos de ordenha, uma terceira para obtenção de dados relativos ao funcionamento do equipamento de ordenha, utilizando-se instrumentos especializados ${ }^{1}$ e finalmente uma última para anotação das características individuais dos animais.

Foram coletadas 3.987 amostras de leite oriundas de 2.657 vacas em lactação em três momentos diferentes. Dessa forma, para cada animal, colheu-se, pelo menos, uma amostra, tendo-se o cuidado de excluir as vacas que apresentavam mastite clínica no momento da coleta ou em tratamento com infusão intramamária. As datas das coletas não foram definidas previamente, sendo as amostras de leite coletadas aleatoriamente em todos os estádios de lactação. Colheram-se aproximadamente $10 \mathrm{ml}$ de leite, de cada quarto mamário, utilizando-se frascos específicos contendo o conservante Bronopol $\AA$, que foram acondicionados em caixas isotérmicas, com gelo reciclável, e transportados em até 24 horas para o laboratório, conforme recomendação de Brito (2001). A CCS foi realizada em equipamento automatizado por

${ }^{1}$ Medidor de vazão da bomba de vácuo Westfalia ${ }^{\circledR}$, Pulso Test Westfalia ${ }^{\circledR}$ e Surge ${ }^{\circledR}$ Digital Vacuum 
meio de citometria de fluxo ${ }^{2}$ de acordo com o IDF (Milk..., 1995).

Para a análise dos fatores de risco, foram utilizados modelos de regressão logística descritos por Frankena e Graat (1997). A estratégia para construção do modelo final de regressão logística foi baseada em Frankena e Graat (1997). Foram realizadas análises bivariadas para testar associações entre cada variável independente do modelo de regressão logística. Foi utilizado o teste qui-quadrado para as variáveis categóricas. Os critérios de decisão para a escolha das variáveis testadas no modelo de regressão logística foram aqueles que ofereciam explicação biológica coerente para o aumento da CCS e que na associação apresentaram $\mathrm{P}<0,05$. Após a seleção das possíveis variáveis independentes, aplicou-se uma série de modelos de regressão logística, tendo como variável dependente a CCS e como variáveis independentes os fatores de risco relacionados às características do rebanho, práticas de manejo de ordenha, procedimentos de controle e prevenção da mastite e uso do equipamento de ordenha. Após a seleção do modelo final de regressão logística, foi observado o coeficiente beta $(\beta)$ de cada variável independente para se estimar o grau de risco (Odds ratio; OR).

O número máximo de variáveis independentes usadas nos modelos foi calculado em função do número de animais classificados de acordo com a CCS abaixo ou acima de 200.000 células $/ \mathrm{ml}$. As análises estatísticas foram realizadas utilizandose o programa estatístico SPSS 8.0 (Statistical..., 1998).

\section{RESULTADOS E DISCUSSÃO}

Os valores da média, mediana e desvio-padrão da CCS foram 608.000, 219.000 e 967.000 células $/ \mathrm{ml}$, respectivamente. Considerando como ponto de corte 200.000 células $/ \mathrm{ml}$ para classificar animais provavelmente infectados, $2.063(52 \%)$ amostras de leite de animais apresentaram resultados acima de 200.000 células $/ \mathrm{ml}$. Mesmo levando em consideração a variação da CCS em função da ordem de parto e período de lactação, conforme verificado por

${ }^{2}$ Bentley - Somacount 300
Schepers et al. (1997) e Laevens et al. (1997), os resultados demonstram grande variação dos valores de CCS e sugerem a presença de animais livres e com infecção intramamárias. Entre estes últimos, pode variar o número de quartos mamários infectados e o patógeno envolvido na infecção, pois estes provocam processos inflamatórios com intensidades diferentes (Souza et al., 2005a).

No primeiro momento das análises, de acordo com as respostas obtidas com o questionário e com os resultados da CCS, 36 variáveis explicativas foram associadas $(\mathrm{P}<0,05)$ à contagem de células somáticas acima de 200.000 células $/ \mathrm{ml}$. No segundo momento, uma série de modelos de regressão logística foi aplicada, tendo sido selecionadas para o modelo final 10 variáveis. A escolha das variáveis usadas no modelo de regressão logística foram as que ofereciam explicação biológica coerente para o aumento da CCS e que apresentaram associação significativa $(\mathrm{P}<0,05)$ com $\mathrm{CCS}$ acima de 200.000 células/ml no teste do qui-quadrado.

As variáveis usadas para identificação dos fatores de risco para CCS acima de 200.000 células/ml no modelo final de regressão logística são apresentadas na Tab. 1 .

Foram identificados fatores de risco relacionados ao animal, ao manejo e ao equipamento de ordenha. $\mathrm{O}$ único fator de risco associado às características individuais da vaca foi a profundidade do úbere. Animais com a base do úbere abaixo ou junto ao jarrete apresentaram 1,73 vezes mais chances de terem a CCS acima de 200.000 células/ml que os animais com a base do úbere acima do jarrete. Provavelmente, isso ocorre pelo aumento da exposição das extremidades dos tetos aos microrganismos ambientais.

Peller et al. (2000) identificaram fatores de risco para mastite subclínica e clínica associados com o aumento do número de parições, início e final de lactação, escape de leite pelos tetos observado durante a ordenha e alta produção de leite. Neste estudo, essas características não foram identificadas como fatores de risco, entretanto o posicionamento da base do úbere junto ou abaixo do jarrete pode ser reflexo da idade ou do número de partos e da alta produção de leite. 
Os fatores de risco relacionados ao equipamento de ordenha foram existência de rachaduras ou fissuras nas partes de borracha do equipamento, estado inadequado das teteiras e deficiência na limpeza dos pulsadores. A troca periódica dos componentes de borracha e teteiras do equipamento bem como o treinamento dos ordenhadores quanto à utilização e manutenção do equipamento de ordenha foram identificados por Souza et al. (2005a) como pontos importantes no controle e na prevenção de mastite. As teteiras, em particular, podem funcionar como um elemento de transferência de bactérias de uma vaca infectada para uma sadia. O surgimento de fissuras nas partes de borracha do equipamento de ordenha facilita o acúmulo de leite e dificulta a aderência no teto, permitindo a entrada de ar no sistema e a queda do conjunto de teteiras. Souza et al. (2005a) observaram que, em 79 rebanhos leiteiros ordenhados mecanicamente, $32 \quad(40,5 \%)$ tinham equipamentos de ordenha com no mínimo cinco anos de uso e $28(35,4 \%)$ não realizavam ou realizavam de forma esporádica a manutenção do equipamento.

O segundo maior risco identificado foi a inexistência de programas de treinamento dos ordenhadores para a realização da ordenha. Nas propriedades onde os ordenhadores não recebiam qualquer tipo de treinamento, tais como: explicações acerca dos procedimentos adequados durante a ordenha, uso e manutenção do equipamento de ordenha, realização do exame dos primeiros jatos de leite em todos os quartos ou realização do California Mastitis Test, os animais apresentaram 2,51 vezes mais chances de apresentar a CCS acima de 200.000 células $/ \mathrm{ml}$.

A busca pelo aperfeiçoamento da mão-de-obra deve ser um dos objetivos do produtor de leite para se tornar competitivo no mercado. Com ênfase no controle e na prevenção de mastite, Souza et al. (2005a) observaram que os procedimentos de higiene durante a ordenha não estavam bem difundidos em rebanhos leiteiros. Nesse estudo, de 175 rebanhos, o tratamento do úbere na secagem, o exame dos primeiros jatos e a desinfecção dos tetos após a ordenha só foram observados em $48(27,4 \%), 45(25,7 \%)$ e 54 $(30,9 \%)$ rebanhos, respectivamente. Segundo os autores, tais procedimentos são fundamentais no controle e na prevenção da mastite e merecem treinamento específico.

Tabela 1. Modelo final de regressão logística tendo como variável dependente valores da contagem de células somáticas do leite de vacas acima ou abaixo de 200.000 células $/ \mathrm{ml}$

\begin{tabular}{|c|c|c|}
\hline Fator de risco & OR & $\mathrm{P}$ \\
\hline Base do úbere junto ou abaixo do jarrete & 1,73 & $*$ \\
\hline $\begin{array}{l}\text { Presença de rachaduras ou fissuras nas partes de borracha do equipamento de } \\
\text { ordenha }\end{array}$ & 2,45 & $* * *$ \\
\hline Estado inadequado das teteiras do equipamento de ordenha & 1,48 & $* *$ \\
\hline Deficiência de limpeza freqüente dos pulsadores & 1,41 & $*$ \\
\hline Falta de treinamento dos ordenhadores para realização de ordenha & 2,51 & $* *$ \\
\hline $\begin{array}{l}\text { Não utilização de serviço laboratorial (microbiologia) para diagnóstico dos casos } \\
\text { de mastite (desconhecimento dos patógenos causadores de mastite no rebanho) }\end{array}$ & 1,84 & $* * *$ \\
\hline $\begin{array}{l}\text { Imersão dos conjuntos de teteiras em solução desinfetante entre a ordenha de } \\
\text { animais }\end{array}$ & 2,19 & $* * *$ \\
\hline Inserção total da cânula na aplicação de antibiótico intramamário & 2,64 & $* * *$ \\
\hline Compra de animais para reposição do rebanho & 0,57 & $* * *$ \\
\hline Uso de caneca com retorno para desinfecção dos tetos antes e depois da ordenha & 0,30 & $* * *$ \\
\hline
\end{tabular}

Os rebanhos que não recorriam aos serviços laboratoriais (microbiológico) para o diagnóstico dos casos de mastite apresentaram 1,84 vezes mais chances de os animais obterem CCS acima de 200.000 células/ml que os rebanhos das propriedades em que havia a preocupação de realizar tais exames. Considerando que a mastite é uma doença endêmica em rebanhos leiteiros, a avaliação periódica da saúde do úbere baseada em análises de laboratório para CCS e/ou a identificação dos agentes infecciosos permite(m) maior sucesso no controle e na prevenção da 
doença. Portanto, com o suporte laboratorial, podem-se identificar animais com infecções crônicas ocasionadas, principalmente, pelos patógenos contagiosos da mastite. Com o objetivo de diminuir a ocorrência da mastite no rebanho, esses exames podem auxiliar na tomada de decisões, conforme descrito por Sol et al. (1997) e Osteras et al. (1999). Os procedimentos seriam antecipar o tratamento à secagem, fazer o descarte dos animais-problema e realizar a linha de ordenha. A identificação do tipo de patógeno envolvido é um fator importante, pois, dependendo do agente infeccioso ou do padrão de infecção do rebanho (Brito et al. 1999), podem-se indicar estratégias para controle e prevenção da doença.

Os fatores de risco associados ao manejo foram a imersão do conjunto de teteiras em solução desinfetante entre as ordenhas e a inserção total da cânula da bisnaga de antibiótico como via de aplicação intramamária. Propriedades em que o conjunto de teteiras foi imerso em solução desinfetante entre a ordenha de diferentes animais apresentaram 2,19 vezes mais chance de os animais apresentarem CCS acima de 200.000 células $/ \mathrm{ml}$ que as propriedades que não realizavam essa prática. Provavelmente a matéria orgânica, como leite e sujeiras, em contato com o desinfetante neutralizou o seu princípio ativo. Assim, a solução desinfetante pode ter facilitado a transmissão de patógenos da mastite, contagioso ou ambiental, de um animal infectado para um susceptível por meio do conjunto de teteiras.

O procedimento de inserção total da cânula na aplicação de antibiótico intramamário foi o maior risco identificado no estudo, representando 2,64 vezes mais chance de os animais apresentarem CCS acima de 200.000 células/ml em relação aos submetidos à técnica de inserção parcial da cânula da bisnaga de antibiótico. A adoção correta de inserção da cânula de antibiótico para tratamento à secagem ou de casos clínicos evita a introdução de microrganismos no interior da glândula mamária. A inserção total da cânula pode aumentar o canal do lúmen, levando à maior penetração de bactérias, além de contribuir para que as bactérias presentes no canal do teto sejam introduzidas na cisterna da teta. Estes resultados mostram a importância da realização correta dos procedimentos de tratamento intramamário para o controle da mastite. A importância do manejo, não somente durante a ordenha, foi descrita por Barkema et al. (1999) e Ott e Novak (2001), em estudos sobre fatores de risco para mastite, e evidenciada no presente estudo. A imersão dos tetos em solução desinfetante após a ordenha, o tratamento à secagem de todos os animais, o tratamento imediato dos casos clínicos e a segregação de animais no momento da ordenha (Allore et al., 1998; Berry e Hillerton, 2002) contribuíram para a redução dos casos de mastites. Esses procedimentos não foram identificados como fatores de risco no presente estudo, mas são considerados fundamentais para o controle e a prevenção da enfermidade nos rebanhos leiteiros.

Para fins de controle e prevenção da mastite na população estudada, a separação de animais cuja base do úbere esteja no mesmo nível ou abaixo do jarrete, a manutenção correta do equipamento de ordenha e a identificação de patógenos da mastite, o treinamento dos ordenhadores para realização de ordenha, a não imersão do conjunto de teteiras em solução desifentante entre a ordenha de animais distintos e a correta aplicação de antibiótico intramamário poderiam reduzir os níveis de mastite.

Outros fatores de risco estudados, como a compra de animais para reposição do rebanho e o tipo de aplicador usado na desinfecção dos tetos antes e depois da ordenha, apesar de terem sido significativos no modelo e explicarem biologicamente o aumento da CCS, não resultaram em risco relativo maior que $1 \mathrm{e}$, por isso, não foram caracterizados como fatores de risco.

Sugere-se, assim, que o os principais fatores de risco identificados no presente estudo estavam associados às características regionais como: logística, acesso à assistência técnica especializada, medicamentos e suporte laboratorial e, principalmente, à falta de orientação profissional. Estudos dessa natureza têm importância no sentido de apresentar os principais problemas associados a uma população para uma determinada enfermidade. Para se calcular o efeito de um provável fator de risco, foi levado em consideração o efeito de todos os outros fatores. Uma limitação para esse tipo de estudo é não poder usar todas as variáveis ou informações obtidas para a análise final. 


\section{CONCLUSÕES}

Os principais fatores de risco para ocorrência de mastite subclínica em vacas leiteiras foram as características dos animais, o manejo inadequado, a inexistência de treinamento dos ordenadores, a não utilização de serviços laboratoriais para identificação dos patógenos e o uso de equipamentos de ordenha sem manutenção periódica. Apesar de a metodologia não identificar todos os fatores associados à mastite subclínica, os fatores de risco identificados podem ser priorizados no sentido de aprimorar os programas de controle e prevenção da mastite dos rebanhos.

\section{AGRADECIMENTOS}

À Fundação de Amparo à Pesquisa do Estado de Minas Gerais (FAPEMIG), pelo apoio financeiro para a realização deste trabalho (Projeto EDT 401/05).

\section{REFERÊNCIAS BIBLIOGRÁFICAS}

ALLORE, H.G.; ERB, H.N.; SCHRUBEN, L.W. et al. A simulation of strategies to lower bulk milk tank somatic cell count below 500,000 per mililiter. J. Dairy Sci., v.81, p.694-702, 1998.

BARKEMA, H.W.; VAN DER PLOEG, J.D.; SCHUKKEN, Y.H. et al. Management style and its association with bulk milk somatic cell count and incidence rate of clinical mastitis. J. Dairy Sci., v.82, p.1655-1663, 1999.

BERRY, E.A., HILLERTON, J.E. The effect of selective dry cow treatment on new intramammary infections. $J$. Dairy Sci., v.85, p.112-121, 2002.

BRITO, J.R.F. Coleta de amostras de leite para determinação da composição química e contagem de células somáticas. Juiz de Fora: Embrapa Gado de Leite, 2001. 16p. (Circular Técnica, 62).

BRITO, M.A.V.P.; BRITO, J.R.F.; RIBEIRO, M.T. et al. Padrão de infecção intramamária em rebanhos leiteiros: exame de todos os quartos mamários das vacas em lactação. Arq. Bras. Med. Vet. Zootec., v.51, p.129-135, 1999.

CUNHA, R.P.L.; MOLINA, L.R.; CARVALHO, A.V. et al. Mastite subclínica e relação da contagem de células somáticas com número e lactações, produção e composição química do leite em vacas da raça Holandesa. Arq. Bras. Med. Vet. Zootec., v.60, p.19-24, 2008.

DOHOO, I.R.; LESLIE, K.E. Evaluation of chages in somatic cell counts as indicators of new intramammary infections. Prev. Vet. Med., v.10, p.225-237, 1991.
FRANKENA, K.; GRAAT, E.A.M. Multivariate analysis: logistic regression. In: NOORDHUIZEN, J.P.T.M.; FRANKENA, K.; VAN DER HOOFD, C.M. et al. (Eds). Application of quantitative methods in veterinary epidemiology. Wageningen: Wageningen Press, 1997. p.135-178.

HARMON, R.J. Physiology of mastitis and factors affecting somatic cell counts. J. Dairy Sci., v.77, p.21032113, 1994.

LAEVENS, H.; DELUYKER, H.; SCHUKKEN, Y.H. et al. Influence of parity and stage of lactation on the somatic cell count in bacteriologically negative dairy cows. J. Dairy Sci., v.80, p.3219-3226, 1997.

MILK: enumeration of somatic cells. Brussels: International Dairy Federation, 1995. 8p. (IDF Standard 148A).

OSTERAS, O.; EDGE, V.L.; MARTIN, S.W. Determinants of success or failure in the elimination of major mastitis pathogens in selective dry cow therapy. $J$. Dairy Sci., v.82, p.1221-1231, 1999.

OTT, S.L.; NOVAK, P.R. Association of herd productivity and bulk-tank somatic cell counts in US dairy herds in 1996. J. Am. Vet. Med. Assoc., v.218, p.1325-1329, 2001.

PEELER, E. J.; GREEN, M. J.; FITZPATRICK, J. L. et al. Risk factors associated with clinical mastitis in low somatic cell count British dairy herds. J. Dairy Sci., v.83, p.2464-2472, 2000.

RECOMMENDED mastitis control program. Madison: National Mastitis Council, 2001. Disponível em: $<$ http://www.nmconline.org/docs/NMC10steps.pdf $>$.

Acessado em: 18 mai. 2003

SCHEPERS, A.J.; LAM, T.J.G.M.; SCHUKKEN, Y.H. et al. Estimation of variance components for somatic cell counts to determine thresholds for uninfected quarters. $J$. Dairy Sci., v.80, p.1833-1840, 1997.

SOL, J.; SAMPIMON, O.C.; SNOEP, J.J. et al. Factors associated with bacteriological cure during lactation after therapy for subclinical mastitis caused by Staphylococcus aureus. J. Dairy Sci., v.80, p.2803-2808, 1997.

SOUZA, G.N.; BRITO, J.R.F.; MOREIRA, E.C. et al. Fontes de variação para a contagem de células somáticas em vacas leiteiras. In: CARVALHO, L.A.; ZOCCAL, R.; MARTINS, P.C. et al. Tecnologia e gestão na atividade leiteira. Juiz de Fora: Embrapa Gado de Leite, 2005a. p.121-135.

SOUZA, G.N.; BRITO, J.R.F.; MOREIRA, E.C. et al. Fatores de risco para alta contagem de células somáticas do leite do tanque em rebanhos leiteiros da Zona da Mata de Minas Gerais, Brasil. Arq. Bras. Med. Vet. Zootec., v.57, supl.2, p.251-260, 2005b.

STATISTICAL Package for the Social Science, version 8. 0. Chicago: SPSS, 1998. 